\title{
Influence of shoulder pain on muscle function: implications for the assessment and therapy of shoulder disorders
}

\author{
Filip Struyf $\cdot$ Enrique Lluch $\cdot$ Deborah Falla $\cdot$ \\ Mira Meeus $\cdot$ Suzie Noten $\cdot$ Jo Nijs
}

Received: 6 October 2014 / Accepted: 18 November 2014 / Published online: 28 November 2014

(C) Springer-Verlag Berlin Heidelberg 2014

\begin{abstract}
Shoulder pain is often a challenging clinical phenomenon because of the potential mismatch between pathology and the perception of pain. Current evidence clearly emphasizes an incomplete understanding of the nature of shoulder pain. Indeed, the effective diagnosis and treatment of shoulder pain should not only rely upon a detailed knowledge of the peripheral pathologies that may be present in the shoulder, but also on current knowledge of pain neurophysiology. To assess and treat shoulder pain, a comprehensive understanding of the way in which pain is processed is essential. This review reflects modern pain neurophysiology to the shoulder and aims to answer the following questions: why does my shoulder hurt? What is the impact of shoulder pain on muscle function? What are the implications for the clinical examination of the shoulder? And finally, what are the clinical implications for therapy? Despite the increasing amount of research in this area, an in-depth understanding of the bidirectional
\end{abstract}

Communicated by Nigel A.S. Taylor.

F. Struyf $(\bowtie) \cdot$ M. Meeus $\cdot$ S. Noten

Department of Rehabilitation Sciences and Physiotherapy,

Faculty of Medicine and Health Sciences, University of Antwerp,

Universiteitsplein 1, 2610 Wilrijk, Belgium

e-mail: filip.struyf@uantwerpen.be

F. Struyf $\cdot$ E. Lluch $\cdot$ M. Meeus $\cdot$ S. Noten $\cdot$ J. Nijs

Pain in Motion Research Group, Brussels, Belgium

E. Lluch

Department of Physical Therapy, University of Valencia,

Valencia, Spain

D. Falla

Pain Clinic, Center for Anesthesiology, Emergency and Intensive

Care Medicine, University Hospital Göttingen, Göttingen,

Germany nociception-motor interaction is still far from being achieved. Many questions remain, especially related to the treatment of nociception-motor interactions.

Keywords Shoulder pain $\cdot$ Neurophysiology $\cdot$ Motor output

\section{Introduction}

Shoulder pain is the third most common musculoskeletal condition, with enormous social-economic costs, resulting from a significant effect on the patient's ability to work and perform activities of daily living (Greenberg 2014). The lifetime prevalence of shoulder pain in the general population is as high as $67 \%$ (Luime et al. 2004, 2005; Ryall et al. 2006). The exact cause of shoulder pain is often indefinable, partly due to the vast amount of structures potentially involved (Dean et al. 2013). Although current evidence

M. Meeus

Department of Rehabilitation Sciences and Physiotherapy, Faculty of Medicine and Health Sciences, Ghent University, Ghent, Belgium

J. Nijs

Departments of Human Physiology and Physiotherapy, Faculty of Physical Education and Physiotherapy, Vrije Universiteit Brussel, Brussels, Belgium

J. Nijs

Department of Physical Medicine and Physiotherapy, University Hospital Brussels, Brussels, Belgium 
clearly emphasizes an incomplete understanding of the nature of shoulder pain, clinicians often use unsubstantiated conjectures to explain to patients why their shoulder hurts (Dean et al. 2013), such as presuming a specific anatomical structure to be the cause of their pain. In addition, shoulder pain is often a challenging clinical phenomenon because of the potential mismatch between pathology and the perception of pain (Gwilym et al. 2011). Indeed, the effective diagnosis and treatment of shoulder pain should not only rely on a detailed knowledge of the peripheral pathologies that may be present in the shoulder (i.e., rotator cuff pathology, adhesive capsulitis or labral lesion), but also on current knowledge of pain neurophysiology.

This review first focuses on how pain can be generated, propagated, and modified around the shoulder and second, it describes the way pain affects motor output and proprioception. Consequently, common clinical questions will be addressed, such as why does the patients' shoulder hurt? How does this relate to the patients' motor performance? Finally, clinical implications for assessing and treating patients with shoulder pain will be presented.

Why does my shoulder hurt? Modern pain neurophysiology applied to the shoulder: part I

Where does pain perception around the shoulder originate? Unfortunately, this question is not easily answered, since the neuroanatomical and biochemical basis of shoulder pain is interminable and not completely understood (Dean et al. 2013). To assess and treat shoulder pain, a comprehensive understanding of the way in which pain is processed is essential. Hence, a brief introduction of pain neurophysiology is a requisite for clinicians managing patients with shoulder pain.

There is a large variety of peripheral sensory receptors present around the (shoulder) joint, such as mechanoreceptors, thermoreceptors, and nociceptors (Schaible and Grubb 1993). Historically, nociceptors were defined as receptors that respond preferentially to noxious stimuli and which have a high threshold to adequate thermal, mechanical or chemical stimuli (Sherrington 1906). But in fact there is a large degree of overlap between the characteristics of nociceptors and mechanoreceptors (Cooper et al. 1993), such that nociceptors are then often defined as high threshold mechanoreceptors. Basic knowledge of the location and types of receptors in the shoulder can aid clinicians to understand the way in which tissue pathology may produce clinical pain. Unfortunately, literature regarding the distribution of receptors in human shoulder muscles is lacking and most available information is derived from animal studies. For instance, we know that the rotator cuff of rabbits has a high density of nociceptors around its humeral insertion, especially around the M. supraspinatus
(Minaki et al. 1999). In addition, Golgi tendon organs and muscle spindles are present at the musculotendinous junction of the M. supraspinatus in mice (Backenkohler et al. 1996). Although derived from animal studies, we see that together with extensively innervated glenohumeral ligaments (Guanche et al. 1999), glenohumeral capsule (Backenkohler et al. 1996; Guanche et al. 1999; Hashimoto et al. 1994; Solomonow et al. 1996; Tarumoto et al. 1998), subacromial bursae (Ide et al. 1996; Soifer et al. 1996), long head of the biceps tendon (Alpantaki et al. 2005; Tosounidis et al. 2010), and coraco-acromial ligaments (Konttinen et al. 1992; Tamai and Ogawa 1985), it is clear that the amount of mechanoreceptors is positively correlated to the zones where sensory control is the most important due to increased biomechanical stress (Backenkohler et al. 1996).

In the event of a shoulder trauma, injury or pathology, substances such as substance $\mathrm{P}$, potassium, serotonin, bradykinin, histamine and prostaglandins (i.e., $\mathrm{PGE}_{1}, \mathrm{PGE}_{2}$, $\mathrm{PGI}_{2}, \mathrm{PGD}_{2}$ ) will increase the responsiveness of nociceptive neurons to their normal input, a phenomenon known as peripheral sensitization (Dean et al. 2013). These substances are released from damaged tissue cells, the primary afferents themselves, thrombocytes and immune cells (as part of the inflammatory response), and generally work by altering the ion channel function of the nociceptive afferents. The net result is that nociceptors will be activated in response to non-nociceptive, subthreshold inputs like gentle touch (e.g., during palpation) or mid-range shoulder movements (e.g., during clinical tests of the shoulder). This can be viewed as a protective and adaptive action of the immune and peripheral nervous system, allowing damaged tissues to initiate recovery processes. However, this important physiological mechanism may impact upon clinicians' ability to diagnose shoulder injuries accurately, especially when differentiating neighboring tissues to establish a patho-anatomical diagnosis. Within this context, the subjectivity and the lack of reliability and the low diagnostic accuracy of the diagnostic tests for most shoulder disorders (Hegedus et al. 2012) may be explained by a change in mechanosensitivity of the tissues in and around the shoulder girdle, which might account for the often unpredictable and disproportionate pattern of pain provocation in response to mechanical testing.

Besides this physiological hypersensitivity at the site of injury (primary hyperalgesia), hypersensitivity to mechanical stimuli may also occur outside of the original zone of injury (Ali et al. 1996), often referred to as secondary hyperalgesia. Whereas primary hyperalgesia is the result of peripheral sensitization, implying increased spontaneous activity, decreased activation threshold of the nociceptive fibers, increased responsiveness to supra-threshold stimuli, and increased local release of neuropeptides upon 
stimulation and recruitment of silent nociceptive fibers (Konttinen et al. 1994), secondary hyperalgesia rather reflects the involvement of the central nervous system, given the fact that enhanced responses to afferent inputs are present in non-injured regions adjacent to or even remote from initial problem. Continuously increased nociceptive impulse activity may lead to peripheral and subsequently long-lasting central sensitization. Central sensitization is defined as "an amplification of neural signaling within the central nervous system that elicits pain hypersensitivity" (Woolf 2011), "increased responsiveness of nociceptive neurons in the central nervous system to their normal or subthreshold afferent input" (Merskey and Bogduk 1994), or "an augmentation of responsiveness of central neurons to input from unimodal and polymodal receptors" (Meyer et al. 1995). Such definitions originate from laboratory research, but the awareness that the concept of central sensitization should be translated to the clinic is growing (Nijs et al. 2010, 2014a, b). Sensitization of dorsal horn neurons results in secondary hyperalgesia, explaining increased sensitivity to stimuli not only in the anatomical region of primary nociception (i.e., the injured or pathological tissue), but also in segmentally related regions outside the primary zone of nociception. These alterations in the central nervous system further contribute to the poor reliability and validity of shoulder testing in clinical practice and research settings.

In the acute stage following trauma or injury, primary and secondary hyperalgesia is an adaptive response of the nervous system, preventing further damage and hence facilitating tissue healing. Following this initial stage of trauma or injury, characterized by inflammation and early tissue repair, the sensitized peripheral (primary nociceptors) and central nervous system (dorsal horn neurons) should reset to their initial mode of 'normal' sensitivity, resulting in a restoration of the dominance of the descending nociceptive inhibitory systems over the descending nociceptive facilitatory action (Yarnitsky et al. 2014). Unfortunately, the nervous system modus fails to reset in some patients. If the primary source of nociception disappears (e.g., when tissues are healing properly and the inflammatory phase has resolved), the primary hyperalgesia often disappears, but this can be camouflaged by the ongoing secondary hyperalgesia. Moreover, in many cases the secondary hyperalgesia even spreads to segmentally unrelated areas, resulting in widespread central sensitization. In such cases, central sensitization is no longer restricted to the dorsal horn neurons, but also manifests itself in the brain and descending nociceptive system (Woolf 2011).

In the case of chronic shoulder pain dominated by central sensitization, minimal sensory input (with or without tissue damage) could be sufficient to initiate pain perception. This may explain the mismatch between the pain experienced and the extent of injury commonly observed in, e.g., patients with shoulder impingement symptoms (Gwilym et al. 2011). A recent systematic review (Sanchis et al., submitted data) supports an emerging key role for central sensitization in unilateral shoulder pain including shoulder impingement syndrome. This review yielded consistent findings supportive of an important role of central sensitization in the chronic pain experienced by those patients. The presence of central sensitization should not only be considered in patients with shoulder impingement, but may also be present in other shoulder disorders such as rotator cuff tendinopathy (Littlewood et al. 2013), frozen shoulder (Struyf and Meeus 2014) and chronic hemiplegic shoulder pain (Roosink et al. 2012). Still, it is important for clinicians to realize that not all patients with chronic shoulder pain are characterized by central sensitization (Schliessbach et al. 2013). Recently, a clinical method for the classifying pain as central sensitization pain, neuropathic or nociceptive pain was developed, based on a body of evidence from original research papers and expert opinion from 18 pain experts from seven different countries (Nijs et al. 2014a, b). These authors proposed an algorithm that may aid clinicians in identifying shoulder pain patients with a clinical picture dominated by central sensitization, rather than ongoing peripheral (shoulder) nociception.

Impact of pain on shoulder muscle function: modern pain neurophysiology applied to the shoulder-part II

Nociception affects both efferent (motor output) and afferent (proprioception) pathways. A comprehensive overview on the interactions between motor control and nociception is beyond the scope of this review and is described elsewhere (Hodges and Tucker 2011; Nijs et al. 2012). However, we will briefly consider these interactions and the clinical implications for the assessment of patients with shoulder pain.

Neurophysiological reviews on nociception-motor interactions (Hodges et al. 2013; Hodges and Tucker 2011; Nijs et al. 2012) indicate that nociceptive stimuli result in cortical transmission of the motor output and affect the activity of the painful muscle. Nociception impairs motor output through central mechanisms: activated neurons in the somatosensory cortex produce a pain-dependent inhibitory input to the primary motor cortex (both ipsilateral and contralateral) (Farina et al. 2001; Valeriani et al. 1999), and tonic muscle nociception results in long-lasting inhibition of the primary motor cortex (Le Pera et al. 2001). Motor cortex inhibition occurs immediately in response to pain, but it fades once levels of perceived pain become stable for a given amount of time and when no further increase in pain perception is expected by the patient (Farina et al. 2001). This implies that motor cortex inhibition reflects 


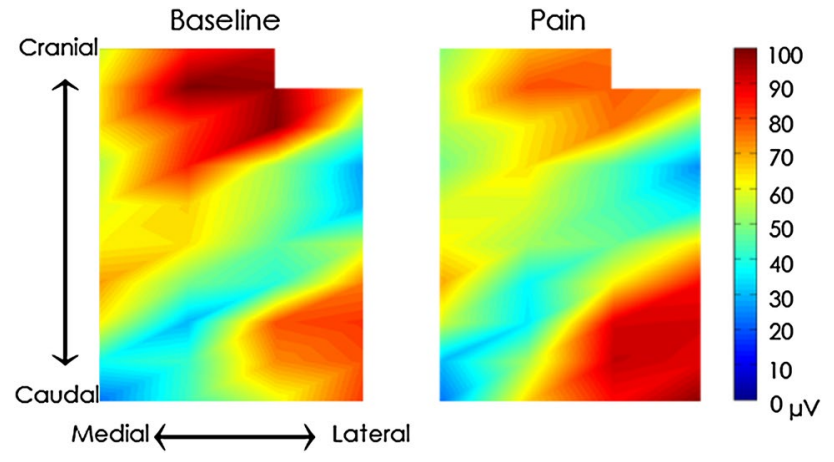

Fig. 1 Change in the spatial distribution of muscle activity with pain: representative topographical maps (interpolation by a factor 8 ) of the EMG root mean square value recorded for one subject for the first $5 \mathrm{~s}$ of the sustained shoulder abduction contraction performed at baseline and following injection of $0.2 \mathrm{ml}$ of hypertonic saline into the cranial and caudal regions of the upper trapezius muscle. Colors are scaled between the minimum and maximum RMS values. Areas of dark blue correspond to areas of low EMG amplitude and dark red to areas of high EMG amplitude. Note the shift of activity towards the caudal region of the muscle with pain. Reprinted with permission from Falla et al. (2009)

variations in pain perception and is no longer necessary when pain severity is stable over time (Farina et al. 2001). Muscle pain-induced inhibition of the motor cortex excitability lasts for many hours after the recovery from pain in humans (Le Pera et al. 2001). In addition, the decreased excitability of the motor cortex induced by cutaneous nociception is preferentially located in the muscles adjacent to the painful area (Farina et al. 2001).

Hence, it comes as no surprise that the nervous system employs a different (i.e., compensatory) muscle activation strategy to maintain motor output during pain. Motor changes in the presence of pain and/or injury present across a spectrum from subtle changes in sharing of load between synergist muscles to a complete avoidance of movement. The adopted motor behavior is generally presumed to enhance protection of the injured/painful tissue, at least in the short term (Hodges and Tucker 2011).

In shoulder pain, subtle changes include delayed activation of subscapularis during arm movement (Hess et al. 2005), redistribution of activity within the trapezius muscle during sustained shoulder contractions (Falla et al. 2008) (Fig. 1), and redistribution of activity between synergists during reaching (Muceli et al. 2014) (Fig. 2) and during sustained shoulder abduction (Bandholm et al. 2008). Such changes may lead to discrete changes in the manner in which movement/forces are produced in the presence of pain. Global changes include reduced function, complete avoidance of a movement or avoidance of participation in activity and are often associated with a range of psychosocial features such as fear avoidance (Lentz et al. 2009).
Fig. 2 Redistribution of activity between synergists with pain: a pain-free volunteers $(n=8)$ performed multi-joint reaching in the horizontal plane using a manipulandum, with the starting point at the centre of the circle. The subject had to reach the 12 targets depicted in a with each reaching movement lasting $1 \mathrm{~s}$ followed by $5 \mathrm{~s}$ rest at the target position before returning to the centre point over $1 \mathrm{~s}$. Subjects performed the task at baseline, and following the injection of isotonic (control) and hypertonic (painful) saline. Saline was injected into the right anterior deltoid (DAN) muscle. b Representative example of endpoint trajectories recorded from one subject during the baseline (blue), control (magenta), and painful (red) conditions. Note that pain did not affect the kinematics of this controlled task. c Directional tuning of the EMG envelope peak value recorded from 12 muscles during the baseline (blue), the control (magenta), and pain (red) conditions. The "shrinking" of the pain curves of the DAN muscle was due to a consistent decrease in the EMG activity of this muscle across subjects. Other muscles also changed their activity; however, the direction of change was different across subjects, demonstrating the variability in subject response. For example, the activity of the posterior deltoid (DPO) increased during pain in three subjects while it decreased in five subjects, so that on average it was unchanged. d Representative data from a single subject showing a decrease in DAN activity with a simultaneous increase in DPO activity during pain. e In contrast, representative data from another subject show that decreased DAN activity occurred together with a decrease in DPO activity during pain. Reprinted with permission from Muceli et al. (2014). Brachioradialis (BIO), anconeus (ANC), medial head of the biceps brachii (BME), lateral head of the biceps brachii (BLA), brachialis (BIA), lateral head of the triceps brachii (TLA), long head of the triceps brachii (TLO), medial deltoid (DME), pectoralis major (PEC), posterior deltoid (DPO), and latissimus dorsi (LAT)

Although early theories proposed stereotypical changes in sensorimotor function (Lund et al. 1991; Roland 1986), individual variation is a common feature of the most musculoskeletal pain conditions (Hodges and Tucker 2011), including shoulder pain. For instance, recent work (Muceli et al. 2014) shows that some, but not all, people use the same muscle synergies during reaching tasks when pain is induced in their shoulder compared to a non-painful condition. This is consistent with the observation that some people perform a particular task in a more stereotyped manner than others (Moseley and Hodges 2006). Those individuals with less variable motor programs seem to be more prone to develop pain as they overuse the same strategy rather than taking advantage of the redundancy of the motor system (Moseley and Hodges 2006).

Changes in motor control could perpetuate injury/pain if the altered motor strategy or movement leads to excessive loading of tissues. For instance, a lack of posterior tilting of the scapula has frequently been associated with the incidence of shoulder impingement symptoms. It is hypothesized that a reduced scapular posterior tilt reduces the subacromial space and thus potentially creates soft tissue impingement (chronic nociception) (Struyf et al. 2011a). There is moderate evidence that the upper trapezius shows increased activity among patients suffering from shoulder impingement symptoms, and the lower trapezius 
A

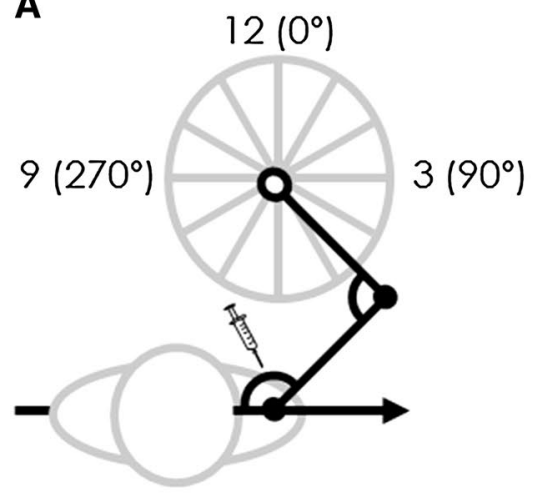

C

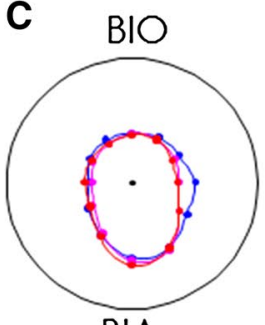

BIA

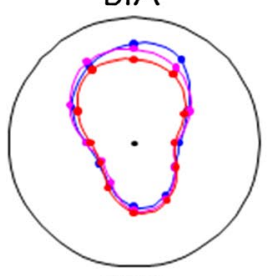

PEC
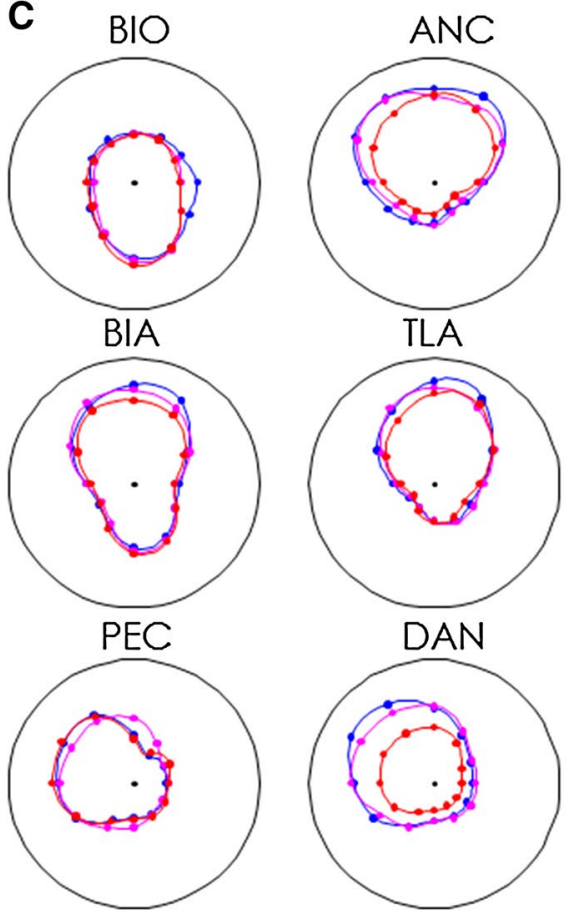

DAN

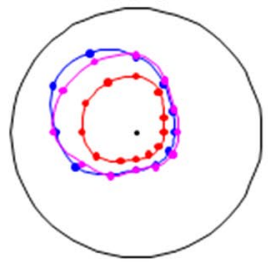

Baseline

D
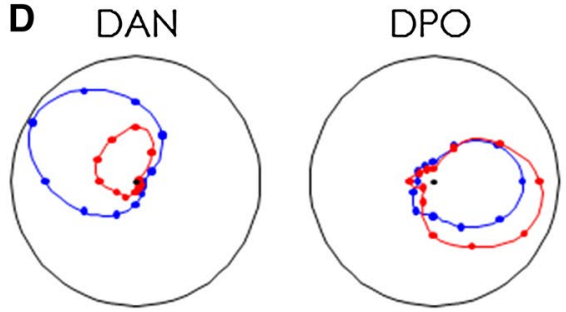

and serratus anterior decreased activity when compared to asymptomatic subjects (Struyf et al. 2014). Although it is difficult to reason about this type of muscular activity change, in theory, by elevating the clavicle and by superiorly translating the scapula (upper trapezius activity), patients could perform substantial shoulder elevation even though the humeral head migrates superiorly.
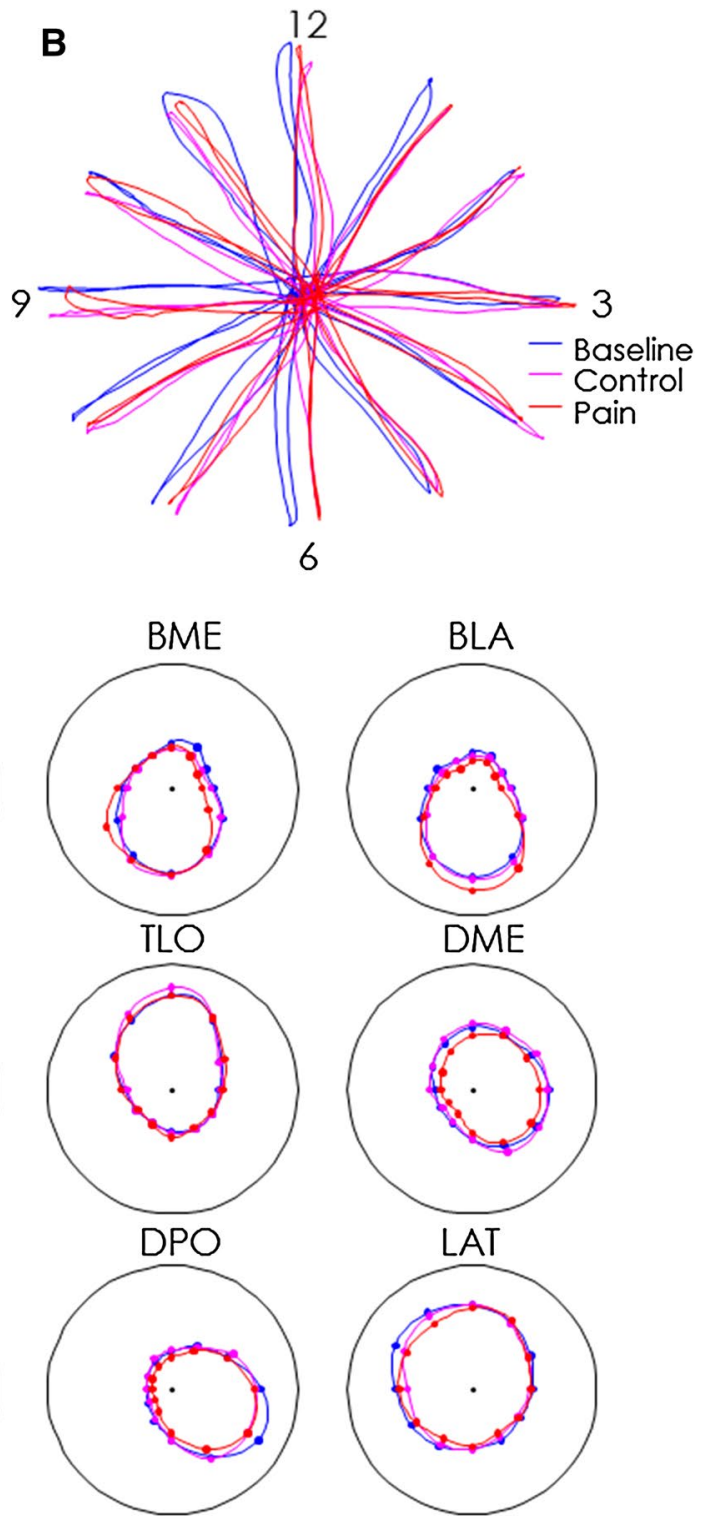

Control

Pain

E
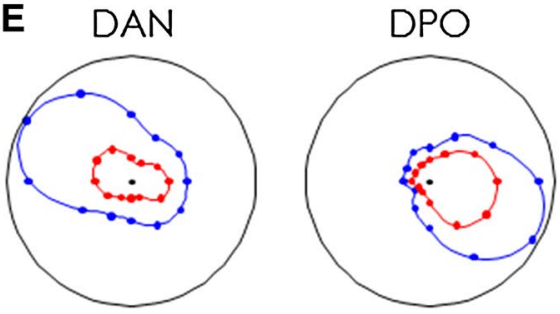

Some kinematic studies have even shown different movement patterns in both the painful and pain-free shoulder (Hebert et al. 2002; Lukasiewicz et al. 1999), suggesting that an altered neuromuscular strategy might affect both shoulders. Indeed, Wadsworth et al. (Wadsworth and Bullock-Saxton 1997) observed a significant delayed recruitment of the serratus anterior muscle on the pain-free 
side in individuals with shoulder pain compared to control subjects. In addition, they did not register any significant differences between the symptomatic or asymptomatic side within the shoulder pain group, emphasizing that injury at one side of the body could be associated with alterations in muscle function on the unaffected side.

Implications for the clinical examination of the shoulder: modern pain neurophysiology applied to the shoulderpart III

If one translates the above knowledge to shoulder pain (testing), a broader picture appears. For example, imagine a tennis player serving for match point. Driven by exalted motivation, he steers his body force through his shoulder for his potentially last serve. Sudden pain arises at the shoulder due to a small tear in the M. supraspinatus tendon. This injury involves a variety of inflammatory mediators being released by damaged cells (as presented above), of which some may activate nociceptors and others give rise to the recruitment of other cells resulting in the release of more facilitatory agents (Costigan and Woolf 2000). This local supraspinatus tendon tissue damage will potentially result in an increased responsiveness of nociceptive neurons to their normal input. Clinically, this patient will be instructed to rest and take medication. However, as it is "expected" from a successful athlete, he will recommence his training sessions ahead of the prescribed rehabilitation schedule, creating some additional pain, which is put aside as "no pain no gain". However, in the presence of ongoing nociception, the strategies used by the central nervous system to control his glenohumeral and scapulothoracic joint (i.e., motor control) will be clearly altered, which could create additional nociception.

If the supraspinatus muscle of our tennis player is injured, one could argue that the alteration of supraspinatus activation will be the direct consequence of soft tissue injury. However, experimental muscle nociception (i.e., hypertonic saline injections) does not appear to impair muscle fiber properties or neuromuscular transmission (Farina et al. 2005), yet can induce a profound inhibition of the painful muscle, refuting peripheral changes as the sole cause of altered motor output in response to nociception.

Afferent pathways (i.e., somatosensory processing including proprioception) are also influenced by tonic muscle nociception (Nijs et al. 2012). Muscle nociceptive input is accompanied by severe reduction of position sense of the hand and by loss of stimulus perception (Rossi et al. 2003). There is some evidence for decreased active joint reposition acuity for patients with chronic rotator cuff pain and for patients with unspecified shoulder pain compared to healthy controls (Fyhr et al. 2014). Thus, our tennis player has recommenced training sessions, but may have reduced proprioception of the upper limb, which could further impair performance.

Furthermore, persistent pain, high expectations, performance anxiety, etc. might induce a stress response in our suffering tennis player, activating his sympathetic nervous system. Chronic amplification of tonic sympathetic activity will induce vasoconstriction in skeletal muscles, abnormal modulation of skeletal muscle contractility, irregular discharge of various proprioceptors (e.g., muscle spindles) (Passatore and Roatta 2006). Adrenaline exerts a weakening effect on slow twitch muscle fibers due to shortening of the muscle fiber twitch force resulting in decreased development of force during subtetanic contractions (Bowman 1980; Roatta et al. 2008). This effect is particularly relevant in postural muscles, which are composed of a high proportion of slow twitch muscle fibers. A sympathetically mediated muscle weakening implies that the neural drive to motor neurons, innervating slow twitch muscle fibers, should be increased to produce the same motor output (Roatta et al. 2008). In addition to influencing fiber contractility, the sympathetic nervous system is known to modulate the discharge of muscle spindles either through an action exerted on the receptors themselves or on their first neurons [reviewed by Akoev (1981)]. Sympathetic activation may reduce the sensitivity of muscle spindles to muscle length changes (Hellstrom et al. 2005; Hunt 1960; Matsuo et al. 1995; Roatta et al. 2002), which implies that the quality of proprioceptive information on muscle length changes is reduced, which should negatively impact on feedback correction of movements.

Several clinical tests have been described to identify lesions in specific tissues, such as the rotator cuff or the subacromial bursa; however, there is little evidence to support their diagnostic value (Hegedus et al. 2008, 2012). The value of such clinical tests has been questioned (Hegedus et al. 2008, 2012; Lewis 2009) since structural pathology has been identified in the shoulder region of many asymptomatic people (Frost et al. 1999; Girish et al. 2011). Thus, on assessment it is difficult to determine whether the patients' symptoms are due to the observed structural failure (Lewis 2009, 2011).

Evaluating muscle function can be useful for monitoring disease progression or the development of secondary disorders. Since a higher risk of injury has been associated with an imbalanced muscular strength profile, evaluating shoulder muscle function may be valuable in physical therapy, orthopedics, rheumatology, and sports medicine to quantify the magnitude of strength deficits (Edouard et al. 2013). Both physiological mechanisms (e.g., neural activation) and muscle structural properties (e.g., muscle fiber crosssectional area) determine strength in human movements that involve maximal or near-maximal muscle force exertion (Aagaard et al. 2002; Hakkinen et al. 1985; Sale 1988; 
Thorstensson et al. 1976a, b). However, it is clear that pain might interfere with muscle strength testing and potentially underestimate true muscle strength. Some patients will contract their muscles with reduced force due to fear of injury. Likewise, poor posture can place rotator cuff and scapular muscles in an altered length tension relationship that could reduce the ability to produce force during muscle strength testing (Tate et al. 2008). However, it is difficult to either identify the amount to which pain or posture affects the results of muscle strength tests or to exclude any pain or posture effect. Concerning posture, scapular positioning may be abnormal in patients with shoulder pain (Struyf et al. 2011a, b), and manual scapular repositioning tests can increase shoulder muscle strength (Tate et al. 2008).

Although pain-induced changes in muscle activation are often accompanied by changes in motor output including decreased maximum force (Graven-Nielsen et al. 2002), decreased force steadiness (Bandholm et al. 2008; Muceli et al. 2011), and decreased movement speed (Bank et al. 2013), for conditions with relatively low mechanical demand, the motor output may not change and the task can be executed in the same manner in the presence of pain (Falla et al. 2007; Muceli et al. 2014; Tucker et al. 2009). This is likely due to a redistribution of activity among synergistic and antagonist muscles. Furthermore, pain may induce a spatial redistribution of activity within the same muscle (decreased firing of some motor units and increased firing of others, de-recruitment of some motor units and recruitment of a new population of motor units) (Falla et al. 2009; Tucker et al. 2009). Thus, testing of tasks with low mechanical demand may be difficult to evaluate due to such compensatory activity. These observations account for deep muscle pain as well as for pain induced in non-muscular tissue (Tucker and Hodges 2009).

Clinical implications for therapy: modern pain neurophysiology applied to the shoulder-part IV

A common intervention for treating shoulder pathology is active exercise (van der Heijden 1999). Programs of supervised exercise provide a clinical benefit both in the short and long term when compared to no treatment or placebo treatment (Brox et al. 1999; Ginn et al. 1997). However, response to exercise is highly variable with responses ranging from excellent outcome to no relevant benefit. People that respond well are likely to be individuals where peripheral nociceptive input is continuing to drive their experience of pain. In contrast, it is important to recognize that people with shoulder pathology who do not respond to exercise interventions or other treatments, such as injections or surgery, may have central sensitization driving their pain experience (Gifford 1998; Gwilym et al. 2011). Since activation of descending nociceptive inhibition reduces nociceptive input to the central nervous system, motor output may be (at least partly) enhanced in these patients when nociception is reduced/alleviated (Nijs et al. 2012). As explained above, chronic nociception inhibits motor output. Thus, motor retraining during chronic nociception might be fruitless. A possible solution to this problem is manual joint mobilization, virtual reality or conventional TENS or medication immediately followed by, or combined with, motor control retraining as it might enable effective motor control retraining (Nijs et al. 2012). Despite the increasing amount of research in this area, an in-depth understanding of the
Fig. 3 Effect of nociception on motor output, resulting in additional nociception

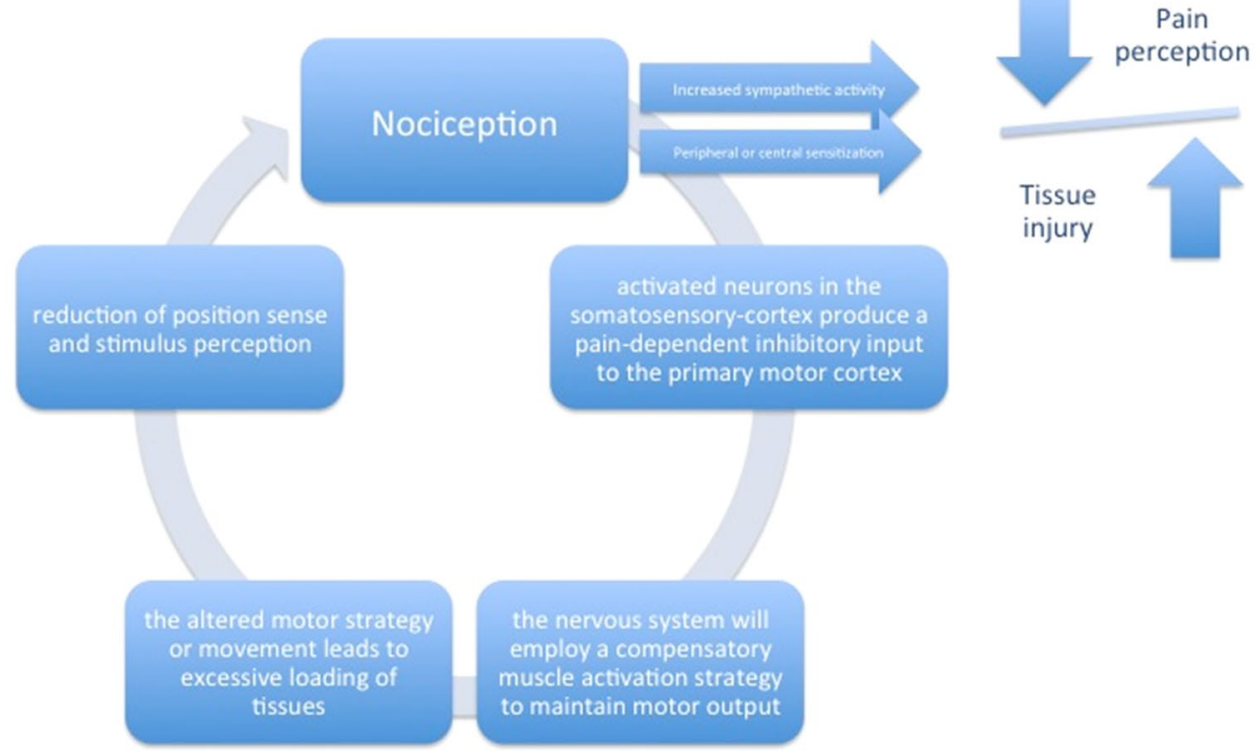


bidirectional nociception-motor interaction is still far from being achieved. Many questions remain, especially related to the treatment of nociception-motor interactions.

\section{Conclusions}

Despite the increasing amount of research in this area, an in-depth understanding of the bidirectional nociceptionmotor interaction is still far from being achieved. However, based on current evidence, nociception activates a paindependent inhibition of the primary motor cortex, resulting in a change in motor strategy around the shoulder. Consequently, this altered movement pattern can lead to overload of peripheral structures, potentially creating more nociceptive input to the somatosensory cortex (Fig. 3). Clinically, these patients will present alterations in their proprioceptive capacities around the shoulder, e.g., a reduced position sense or force sensation.

Acknowledgments I affirm that I have no financial affiliation (including research funding) or involvement with any commercial organization that has a direct financial interest in any matter included in this manuscript, except as disclosed in an attachment and cited in the manuscript.

\section{References}

Aagaard P, Simonsen EB, Andersen JL, Magnusson P, Dyhre-Poulsen $P$ (2002) Increased rate of force development and neural drive of human skeletal muscle following resistance training. J Appl Physiol 93:1318-1326

Akoev GN (1981) Catecholamines, acetylcholine and excitability of mechanoreceptors. Prog Neurobiol 15:269-294

Ali Z, Meyer RA, Campbell JN (1996) Secondary hyperalgesia to mechanical but not heat stimuli following a capsaicin injection in hairy skin. Pain 68:401-411

Alpantaki K, McLaughlin D, Karagogeos D, Hadjipavlou A, Kontakis G (2005) Sympathetic and sensory neural elements in the tendon of the long head of the biceps. J Bone Jt Surg Am 87:1580-1583

Backenkohler U, Halata Z, Strasmann TJ (1996) The sensory innervation of the shoulder joint of the mouse. Ann Anat 178:173-181

Bandholm T, Rasmussen L, Aagaard P, Diederichsen L, Jensen BR (2008) Effects of experimental muscle pain on shoulder-abduction force steadiness and muscle activity in healthy subjects. Eur J Appl Physiol 102:643-650

Bank PJ, Peper CE, Marinus J, Beek PJ, van Hilten JJ (2013) Motor consequences of experimentally induced limb pain: a systematic review. Eur J Pain 2:145-157

Bowman WC (1980) Prejunctional and postjunctional cholinoceptors at the neuromuscular junction. Anesth Analg 59:935-943

Brox J, Gjengedal E, Uppheim G, Bohmer A, Brevik J, Ljunggren A, Staff P (1999) Arthroscopic surgery versus supervised exercises in patients with rotator cuff disease (stage II impingement syndrome): a prospective, randomised, controlled study in 125 patients with 2.5 year follow-up. J Should Elb Surg 8:102-111

Cooper B, Loughner B, Friedman RM, Heft MW, LaBanc J, Fonte A (1993) Parallels between properties of high-threshold mechanoreceptors of the goat oral mucosa and human pain report. Exp Brain Res 94:323-335

Costigan M, Woolf CJ (2000) Pain: molecular mechanisms. J Pain $1: 35-44$

Dean BJ, Gwilym SE, Carr AJ (2013) Why does my shoulder hurt? A review of the neuroanatomical and biochemical basis of shoulder pain. Br J Sports Med 47:1095-1104

Edouard P, Degache F, Oullion R, Plessis JY, Gleizes-Cervera S, Calmels P (2013) Shoulder strength imbalances as injury risk in handball. Int J Sports Med 34:654-660

Falla D, Farina D, Kanstrup Dahl M, Graven-Nielsen T (2007) Muscle pain induces task-dependent changes in cervical agonist/ antagonist activity. J Appl Physiol 102:601-609

Falla D, Arendt-Nielsen L, Farina D (2008) Gender-specific adaptations of upper trapezius muscle activity to acute nociceptive stimulation. Pain 138:217-225

Falla D, Arendt-Nielsen L, Farina D (2009) The pain-induced change in relative activation of upper trapezius muscle regions is independent of the site of noxious stimulation. Clin Neurophysiol 120:150-157

Farina S, Valeriani M, Rosso T, Aglioti S, Tamburin S, Fiaschi A, Tinazzi M (2001) Transient inhibition of the human motor cortex by capsaicin-induced pain. A study with transcranial magnetic stimulation. Neurosci Lett 314:97-101

Farina D, Arendt-Nielsen L, Graven-Nielsen T (2005) Experimental muscle pain decreases voluntary EMG activity but does not affect the muscle potential evoked by transcutaneous electrical stimulation. Clin Neurophysiol 116:1558-1565

Frost P, Andersen JH, Lundorf E (1999) Is supraspinatus pathology as defined by magnetic resonance imaging associated with clinical sign of shoulder impingement? J Should Elb Surg 8:565-568

Fyhr C, Gustavsson L, Wassinger C, Sole G (2014) The effects of shoulder injury on kinaesthesia: a systematic review and metaanalysis. Man Ther. doi:10.1016/j.math.2014.08.006

Gifford L (1998) The 'central' mechanisms. In: Gifford L (ed) Topical issues in pain 1. CNS Press, Falmouth, pp 67-80

Ginn K, Herbert R, Khouw W, Lee R (1997) A randomised, controlled clinical trial of a treatment for shoulder pain. Phys Ther 77:802-811

Girish G, Lobo LG, Jacobson JA, Morag Y, Miller B, Jamadar DA (2011) Ultrasound of the shoulder: asymptomatic findings in men. AJR Am J Roentgenol 197:W713-W719

Graven-Nielsen T, Lund H, Arendt-Nielsen L, Danneskiold-Samsoe B, Bliddal H (2002) Inhibition of maximal voluntary contraction force by experimental muscle pain: a centrally mediated mechanism. Muscle Nerve 26:708-712

Greenberg DL (2014) Evaluation and treatment of shoulder pain. Med Clin N Am 98:487-504

Guanche CA, Noble J, Solomonow M, Wink CS (1999) Periarticular neural elements in the shoulder joint. Orthopedics 22:615-617

Gwilym SE, Oag HC, Tracey I, Carr AJ (2011) Evidence that central sensitisation is present in patients with shoulder impingement syndrome and influences the outcome after surgery. $\mathrm{J}$ Bone $\mathrm{Jt}$ Surg Br 93:498-502

Hakkinen K, Komi PV, Alen M (1985) Effect of explosive type strength training on isometric force- and relaxation-time, electromyographic and muscle fibre characteristics of leg extensor muscles. Acta Physiol Scand 125:587-600

Hashimoto T, Hamada T, Sasaguri Y, Suzuki K (1994) Immunohistochemical approach for the investigation of nerve distribution in the shoulder joint capsule. Clin Orthop Relat Res 273-282

Hebert LJ, Moffet H, McFadyen BJ, Dionne CE (2002) Scapular behavior in shoulder impingement syndrome. Arch Phys Med Rehabil 83:60-69

Hegedus EJ, Goode A, Campbell S, Morin A, Tamaddoni M, Moorman CT 3rd, Cook C (2008) Physical examination tests of the 
shoulder: a systematic review with meta-analysis of individual tests. Br J Sports Med 42:80-92 (discussion 92)

Hegedus EJ, Goode AP, Cook CE, Michener L, Myer CA, Myer DM, Wright AA (2012) Which physical examination tests provide clinicians with the most value when examining the shoulder? Update of a systematic review with meta-analysis of individual tests. Br J Sports Med 46:964-978

Hellstrom F, Roatta S, Thunberg J, Passatore M, Djupsjobacka M (2005) Responses of muscle spindles in feline dorsal neck muscles to electrical stimulation of the cervical sympathetic nerve. Exp Brain Res 165:328-342

Hess SA, Richardson C, Darnell R, Friis P, Lisle D, Myers P (2005) Timing of rotator cuff activation during shoulder external rotation in throwers with and without symptoms of pain. J Orthop Sports Phys Ther 35:812-820

Hodges PW, Tucker K (2011) Moving differently in pain: a new theory to explain the adaptation to pain. Pain 152:S90-S98

Hodges PW, Coppieters MW, MacDonald D, Cholewicki J (2013) New insight into motor adaptation to pain revealed by a combination of modelling and empirical approaches. Eur $\mathrm{J}$ Pain 17:1138-1146

Hunt CC (1960) The effect of sympathetic stimulation on mammalian muscle spindles. J Physiol (Lond) 151:332-341

Ide K, Shirai Y, Ito H, Ito H (1996) Sensory nerve supply in the human subacromial bursa. J Should Elb Surg 5:371-382

Konttinen YT, Santavirta S, Paavolainen P, Antti-Poika I, Tiainen T, Nordstrom D, Hukkanen M (1992) Immunoreactive neuropeptide nerves in ligamentous tissue in chronic shoulder pain. Arch Orthop Trauma Surg 111:341-344

Konttinen YT, Kemppinen P, Segerberg M, Hukkanen M, Rees R, Santavirta S, Sorsa T, Pertovaara A, Polak JM (1994) Peripheral and spinal neural mechanisms in arthritis, with particular reference to treatment of inflammation and pain. Arthritis Rheum 37:965-982

Le Pera D, Graven-Nielsen T, Valeriani M, Oliviero A, Di Lazzaro V, Tonali PA, Arendt-Nielsen L (2001) Inhibition of motor system excitability at cortical and spinal level by tonic muscle pain. Clin Neurophysiol 112:1633-1641

Lentz TA, Barabas JA, Day T, Bishop MD, George SZ (2009) The relationship of pain intensity, physical impairment, and painrelated fear to function in patients with shoulder pathology. J Orthop Sports Phys Ther 39:270-277

Lewis JS (2009) Rotator cuff tendinopathy/subacromial impingement syndrome: is it time for a new method of assessment? Br J Sports Med 43:259-264

Lewis JS (2011) Subacromial impingement syndrome: a musculoskeletal condition or a clinical illusion? Phys Ther Rev 16:388-398

Littlewood C, Malliaras P, Bateman M, Stace R, May S, Walters S (2013) The central nervous system-an additional consideration in 'rotator cuff tendinopathy' and a potential basis for understanding response to loaded therapeutic exercise. Man Ther 18:468-472

Luime JJ, Koes BW, Hendriksen IJ, Burdorf A, Verhagen AP, Miedema HS, Verhaar JA (2004) Prevalence and incidence of shoulder pain in the general population; a systematic review. Scand J Rheumatol 33:73-81

Luime JJ, Koes BW, Miedem HS, Verhaar JA, Burdorf A (2005) High incidence and recurrence of shoulder and neck pain in nursing home employees was demonstrated during a 2-year follow-up. J Clin Epidemiol 58:407-413

Lukasiewicz AC, McClure P, Michener L, Pratt N, Sennett B (1999) Comparison of 3-dimensional scapular position and orientation between subjects with and without shoulder impingement. J Orthop Sports Phys Ther 29:574-583 (discussion 584-576)

Lund JP, Donga R, Widmer CG, Stohler CS (1991) The pain-adaptation model: a discussion of the relationship between chronic musculoskeletal pain and motor activity. Can J Physiol Pharmacol 69:683-694

Matsuo R, Ikehara A, Nokubi T, Morimoto T (1995) Inhibitory effect of sympathetic stimulation on activities of masseter muscle spindles and the jaw jerk reflex in rats. J Physiol (Lond) 483:239-250

Merskey H, Bogduk N (1994) Part III: pain terms, a current list with definitions and notes on usage. In: Merskey H, Bogduk N (eds) Classification of chronic pain. IASP Press, Seattle, pp 209-214

Meyer RA, Campbell IT, Raja SN (1995) Peripheral neural mechanisms of nociception. In: Wall PD, Melzack R (eds) Textbook of pain. Churchill Livingstone, Edinburgh, pp 13-44

Minaki Y, Yamashita T, Takebayashi T, Ishii S (1999) Mechanosensitive afferent units in the shoulder and adjacent tissues. Clin Orthop Relat Res 349-356

Moseley GL, Hodges PW (2006) Reduced variability of postural strategy prevents normalisation of motor changes induced by back pain - a risk factor for chronic trouble? Behav Neurosci 120:474-476

Muceli S, Farina D, Kirkesola G, Katch F, Falla D (2011) Force steadiness in women with neck pain and the effect of short term vibration. J Electromyogr Kinesiol 21:283-290

Muceli S, Falla D, Farina D (2014) Reorganization of muscle synergies during multidirectional reaching in the horizontal plane with experimental muscle pain. J Neurophysiol 111:1615-1630

Nijs J, Van Houdenhove B, Oostendorp RA (2010) Recognition of central sensitization in patients with musculoskeletal pain: application of pain neurophysiology in manual therapy practice. Man Ther 15:135-141

Nijs J, Daenen L, Cras P, Struyf F, Roussel N, Oostendorp RA (2012) Nociception affects motor output: a review on sensorymotor interaction with focus on clinical implications. Clin J Pain 28:175-181

Nijs J, Malfliet A, Ickmans K, Baert I, Meeus M (2014a) Treatment of central sensitization in patients with 'unexplained' chronic pain: an update. Expert Opin Pharmacother 15:1671-1683

Nijs J, Torres-Cueco R, van Wilgen CP, Lluch Girbés E, Struyf F, Roussel N, Van Oosterwijck J, Daenen L, Kuppens K, Vanderweeën L, Hermans L, Beckwée D, Voogt L, Clark J, Moloney N, Meeus M (2014b) Applying modern pain neuroscience in clinical practice: criteria for the classification of central sensitization pain. Pain Physician 17:447-457

Passatore M, Roatta S (2006) Influence of sympathetic nervous system on sensorimotor function: whiplash associated disorders (WAD) as a model. Eur J Appl Physiol 98:423-449

Roatta S, Windhorst U, Ljubisavljevic M, Johansson H, Passatore M (2002) Sympathetic modulation of muscle spindle afferent sensitivity to stretch in rabbit jaw closing muscles. J Physiol (Lond) 540:237-248

Roatta S, Arendt-Nielsen L, Farina D (2008) Sympathetic-induced changes in discharge rate and spike-triggered average twitch torque of low-threshold motor units in humans. J Physiol 586:5561-5574

Roland M (1986) A critical review of the evidence for a pain-spasmpain cycle in spinal disorders. Clin Biomech 1:102-109

Roosink M, Van Dongen RT, Buitenweg JR, Renzenbrink GJ, Geurts AC, Ijzerman MJ (2012) Multimodal and widespread somatosensory abnormalities in persistent shoulder pain in the first 6 months after stroke: an exploratory study. Arch Phys Med Rehabil 93:1968-1974

Rossi S, della Volpe R, Ginanneschi F, Ulivelli M, Bartalini S, Spidalieri R, Rossi A (2003) Early somatosensory processing during tonic muscle pain in humans: relation to loss of proprioception and motor 'defensive' strategies. Clin Neurophysiol 114:1351-1358 
Ryall C, Coggon D, Peveler R, Reading I, Palmer KT (2006) A casecontrol study of risk factors for arm pain presenting to primary care services. Occup Med (Lond) 56:137-143

Sale DG (1988) Neural adaptation to resistance training. Med Sci Sports Exerc 20:S135-S145

Schaible HG, Grubb BD (1993) Afferent and spinal mechanisms of joint pain. Pain 55:5-54

Schliessbach J, Siegenthaler A, Streitberger K, Eichenberger U, Nuesch E, Juni P, Arendt-Nielsen L, Curatolo M (2013) The prevalence of widespread central hypersensitivity in chronic pain patients. Eur J Pain 17:1502-1510

Sherrington CS (1906) Observations on the scratch-reflex in the spinal dog. J Physiol 34:1-50

Soifer TB, Levy HJ, Soifer FM, Kleinbart F, Vigorita V, Bryk E (1996) Neurohistology of the subacromial space. Arthroscopy 12:182-186

Solomonow M, Guanche C, Wink C, Knatt T, Baratta RV, Lu Y (1996) Mechanoreceptors and reflex arc in the feline shoulder. J Should Elb Surg 5:139-146

Struyf F, Meeus M (2014) Current evidence on physical therapy in patients with adhesive capsulitis: what are we missing? Clin Rheumatol 33:593-600

Struyf F, Nijs J, Baeyens JP, Mottram S, Meeusen R (2011a) Scapular positioning and movement in unimpaired shoulders, shoulder impingement syndrome, and glenohumeral instability. Scand J Med Sci Sports 21:352-358

Struyf F, Nijs J, De Graeve J, Mottram S, Meeusen R (2011b) Scapular positioning in overhead athletes with and without shoulder pain: a case-control study. Scand J Med Sci Sports 21:809-818

Struyf F, Cagnie B, Cools A, Baert I, Brempt JV, Struyf P, Meeus M (2014) Scapulothoracic muscle activity and recruitment timing in patients with shoulder impingement symptoms and glenohumeral instability. J Electromyogr Kinesiol 24:277-284

Tamai K, Ogawa K (1985) Intratendinous tear of the supraspinatus tendon exhibiting winging of the scapula. A case report. Clinical Orthop Relat Res 159-163
Tarumoto R, Murakami M, Imai S, Maeda T, Hukuda S (1998) A morphometric analysis of protein gene product 9.5-, substance $\mathrm{P}-$, and calcitonin gene-related peptide immunoreactive innervation in the shoulder joint of the Japanese macaque. J Should Elb Surg 7:522-528

Tate AR, McClure PW, Kareha S, Irwin D (2008) Effect of the scapula reposition test on shoulder impingement symptoms and elevation strength in overhead athletes. J Orthop Sports Phys Ther 38:4-11

Thorstensson A, Grimby G, Karlsson J (1976a) Force-velocity relations and fiber composition in human knee extensor muscles. $\mathrm{J}$ Appl Physiol 40:12-16

Thorstensson A, Karlsson J, Viitasalo JH, Luhtanen P, Komi PV (1976b) Effect of strength training on EMG of human skeletal muscle. Acta Physiol Scand 98:232-236

Tosounidis T, Hadjileontis C, Georgiadis M, Kafanas A, Kontakis G (2010) The tendon of the long head of the biceps in complex proximal humerus fractures: a histological perspective. Injury 41:273-278

Tucker KJ, Hodges PW (2009) Motoneurone recruitment is altered with pain induced in non-muscular tissue. Pain 141:151-155

Tucker K, Butler J, Graven-Nielsen T, Riek S, Hodges P (2009) Motor unit recruitment strategies are altered during deep-tissue pain. J Neurosci 35:10820-10826

Valeriani M, Restuccia D, Di Lazzaro V, Oliviero A, Profice P, Le Pera D, Saturno E, Tonali P (1999) Inhibition of the human primary motor area by painful heat stimulation of the skin. Clin Neurophysiol 110:1475-1480

van der Heijden GJMG (1999) Shoulder disorders: a state-of-the-art review. Ballieres Clin Rheumatol 13:287-309

Wadsworth DJ, Bullock-Saxton JE (1997) Recruitment patterns of the scapular rotator muscles in freestyle swimmers with subacromial impingement. Int J Sports Med 18:618-624

Woolf CJ (2011) Central sensitization: implications for the diagnosis and treatment of pain. Pain 152:S2-S15

Yarnitsky D, Granot M, Granovsky Y (2014) Pain modulation profile and pain therapy: between pro- and antinociception. Pain 155:663-665 